\title{
A comparative experimental study on advance geological prediction between TETSP and TSP303
}

\author{
Yue Liu ${ }^{1}$, Jun-jie $\mathrm{Li}^{1}$ \\ ${ }^{1}$ Zhejiang Design Institute of Water Conservancy and Hydroelectric Power, Hangzhou 310002, China
}

\begin{abstract}
We introduce a new tunnel long distance prediction seismic reflection imaging system called TETSP. We use TETSP and the latest generation TSP303 to advance geological comparison detection in Zhangcun tunnel in Thousand Island Lake-Hangzhou water transfer project. Firstly, we introduce the layout of TETSP observation system and data processing flow. Secondly, we expound the differences between TETSP and TSP303 in aspect of geophone coupling and acoustic interference suppression. Lastly, we analyze the characteristics of reflection anomalies in the karst cave zone of the rock mass. The actual tunnel excavation results verify the reliability of the TSP303 and TETSP prediction. Several conclusions are drawn as follow. Firstly, two kinds of seismic reflection technology both can detect whose wave impedance interface exist significant difference in front of tunnel face, but the TSP303 is more accurate. Secondly, the poor integrity of the rock mass is corresponding to the low velocity of P-wave and S-wave.
\end{abstract}

\section{Introduction}

Thousand Island Lake-Hangzhou water transfer project is a large water conservancy project which takes water from Chun'an County and distributes the water to Xianlin reservoir in Hangzhou City through a water conveyance tunnel. On the way, the water supply from Jiande City, Tonglu County and Fuyang District is considered. The total length of the project line is $112 \mathrm{~km}$, and the design flow is $38.8 \mathrm{~m}^{3} / \mathrm{s}$. Its upstream section of Zhangcun main tunnel passes through Lianhua stream and connects with a buried pipe. The preliminary geological survey shows that the tunnel is mainly composed of sandstone with argillaceous sandstone. The tunnel lithology of the section near Lianhua stream is thick and massive pure limestone, which is easily corroded. A large karst cave is found on the ground surface about $100 \mathrm{~m}$ north of the tunnel line, and a small amount of water is produced in dry season. The local stratum boundary, fracture structure and karst development of the tunnel section have poor integrity and stability, and are prone to various deformation and collapse. To carry out the advance forecast work, we can grasp the geological situation in front of the face, formulate emergency measures for various disasters in advance and reduce the construction risk.

The long distance tunnel prediction technology is based on the theory of seismic elastic wave which drawing on the observation mode of vertical seismic profile (VSP) and according to the principle of equivalent exchange between geophone and focal point. Several receiving points and shooting points are arranged on the tunnel wall to collect seismic reflection data and the mature data processing methods in oil and gas exploration field are used to generate the spatial distribution of wave velocity and reflection layer in the three-dimensional space ahead of the tunnel face. Various earthquake prediction methods can be divided into blasting type like $\mathrm{TSP}^{[1]}$ and hammering type and hammering type like TRT ${ }^{[2]}$. TSP is the earliest popular advanced prediction method during the period of large-scale railway construction in China. It has accumulated a lot of prediction experience in fault fracture zone, tunnel water gushing and karst detection. Although blasting is an ideal way of seismic wave excitation, there are some hidden dangers and low efficiency. TRT is committed to high precision prediction under hammering mode. Its geophone is distributed in the vault and spandrel of tunnel section in space. The detection efficiency of hammering excitation is high. The signal-to-noise ratio can be improved by multiple superposition of data. However, the detection distance is smaller than that of blasting mode, and the sensitivity of geophone is required to be higher.

Many domestic scholars are also engaged in the research of tunnel advance prediction system. Liu et al. ${ }^{[3]}$ developed TGP whose observation system is the same as TSP. Its geophone adopts butter coupling, and its installation efficiency is higher than that of TSP. However, TGP only adopts velocity sensor commonly used in surface seismic exploration, which has low sensitivity and narrow acquisition data spectrum. Zhao et al. ${ }^{[4]}$ developed TST imaging system whose source excitation mode is flexible such as hammer, vibroseis or blasting, but the designed source point is close to the tunnel face, so the risk of data acquisition is relatively high. Wang et al. ${ }^{[5]}$ developed AGI-T3 with reference to TSP and TRT observation system. The system equipment is the lightest and uses wireless mode to transmit data. It is an economic

Email: 1y7088@mail.zdwp.net 
and portable forecasting method. However, the data processing stage lacks anti filtering processing for the signal, moreover, the position of AGI-T3 wave velocity variation curve is inconsistent with the strong reflection layer of migration profile, which affects the detection resolution to a certain extent ${ }^{[6]}$. Wang et al. ${ }^{[7]}$ developed TETSP based on the characteristics of TGP and TSP in recent years, which uses acceleration sensor and clay coupling geophone to collect data with higher signal-tonoise ratio. There are few literatures about TETSP and no report on comparative test with TSP. This paper takes the advanced detection of Zhangcun main tunnel of Thousand Island Lake-Hangzhou water transfer project as an example, the characteristics of TETSP and the difference between TETSP and TSP303 are discussed. The characteristics of original data and forecast effect of TETSP and TSP303 are compared and analyzed.

\section{The principle, observation system design and characteristics of TETSP}

The detection principle of TETSP is the same as that of TSP, which uses explosives to excite elastic waves, and receives three component reflection signals of $\mathrm{P}$-wave and $\mathrm{S}$-wave from space through high sensitivity geophone. After data processing, the spatial distribution law of wave velocity and reflection layer is obtained, so as to infer the nature and scale of unfavorable geology in front of the tunnel. The joint observation system of TETSP and TSP is shown in figure 1, receiver is installed on both sides of the tunnel wall. The depth of the receivers of TETSP and TSP303 is $1.5 \mathrm{~m}$ and $2 \mathrm{~m}$ respectively. The drilling angle is slightly upward. There are 24 blast holes designed with an inclination of $20^{\circ}$ downward. The channel spacing is $1.5 \mathrm{~m}$ and hole depth are $1.2 \mathrm{~m}$ to $1.5 \mathrm{~m}$ higher than the tunnel bottom. In addition, due to the poor quality of the receiving hole on the opposite side of the shot hole, only a single detector was used in the TETSP.

Shot hole number

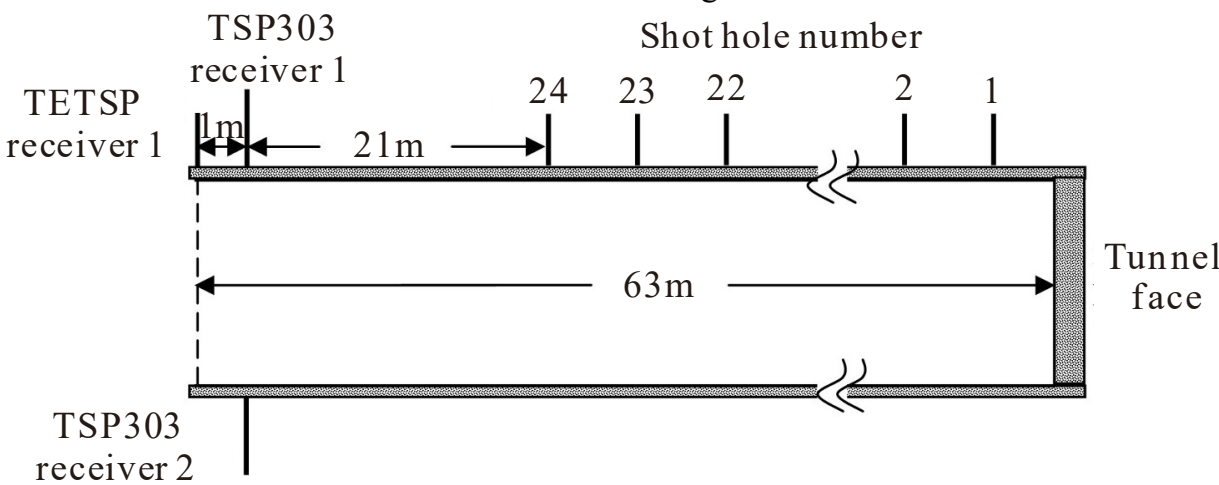

Figure 1. Joint observation system of TETSP and TSP

TSP303 is the latest generation of TSP equipment, the detector is placed in the receiver hole with a reusable casing which is equipped with an plastic anchor instead of a pre processed steel pipe. During the specific operation, anchoring agent is put into the receiving hole, and then the geophone and plastic anchor are inserted into the casing. The sleeve is rotated clockwise to fix the geophone on the compacted anchoring agent. After data acquisition, the geophone can be taken out by turning the detector anticlockwise. The coupling method improves the installation efficiency of TSP geophone and reduces the detection cost to one tens of the original. When TETSP geophone is installed, a small amount of clay is inserted into the bottom of the hole, and then the detector is filled with clay. The installation time of TETSP geophone is shorter than that of TSP303.

\section{Analysis of data processing methods and forecast results of TETSP and TSP303}

TETSP data processing process is similar to TSP303, which uses filtering method to remove noise, pick up direct wave to determine wave velocity reference value, and recover amplitude information through diffusion compensation and inverse filtering, the Radon transform is used to extract the echo signal from the front of the tunnel face and near the tunnel, the velocity analysis method is used to pick up the reflected wave, and the Kirchhoff migration imaging technology is used to extract the reflection layer. TSP303 uses two dimensional filtering method to filter the acoustic energy, so as to improve the signal-to-noise ratio of the data. When the quality of the collected data is poor, there will still be a lot of residual noise after filtering, which leads to false reflection easily extracted in anti-Q filtering, resulting in false alarm. TETSP directly cuts off the subsequent signal of acoustic wave, which greatly suppresses the interference, but also loses some effective deep reflection information.

The seismic reflection method detection corresponds to the pile number $\mathrm{K} 12+850$ of Zhangcun main tunnel face. The observation system is arranged for the tunnel section of class III2 sandstone mixed with argillaceous sandstone, with thin layer as the main part, joint fissure development of rock mass and local crushing. Figure 2 and figure 3 respectively show the detection results of TETSP and TSP303 in section $\mathrm{K} 12+850-\mathrm{K} 12+620$ of Zhangcun main tunnel. As shown in figure 2, the minimum values of physical and mechanical indexes of TETSP are mainly concentrated in sections $\mathrm{K} 12+833-$ $\mathrm{K} 12+813, \mathrm{~K} 12+755-\mathrm{K} 12+738$ and $\mathrm{K} 12+655-\mathrm{K} 12$ +651 . The abnormal area of TSP303 is mainly located in 


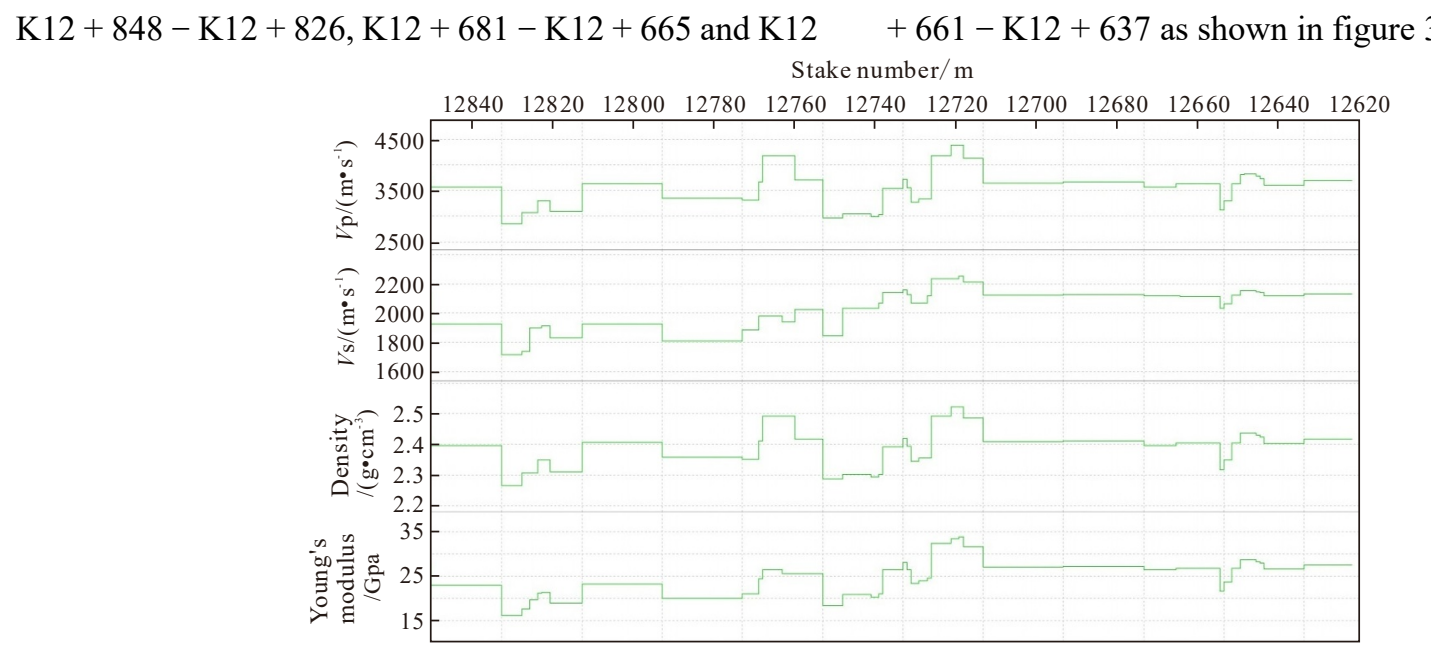

Figure 2. Detection results of TETSP at stake number K12+850-K12+620 in ZhangCun tunnel

Table 1 shows the analysis of the detection results of TETSP and TSP303 and the comparison of actual excavation results. As shown in table 1, the surrounding rock in the detection area of seismic reflection wave method is mainly thick block pure limestone, and the integrity of rock mass is generally good with weak dissolution exists locally, among which $\mathrm{K} 12+850-\mathrm{K} 12$ +827 section is the transition section between sandstone and limestone with poor rock quality; K12+620-K12+ 661 section is limestone with filling karst cave; large karst cavity is developed outside the left wall of $\mathrm{K} 12+684-$ $\mathrm{K} 12+661$ section, but the intersection angle with tunnel axis is small, and the maximum intersection radius with left upper part of tunnel face is about $1 \mathrm{~m}$. TETSP and TSP303 delineated three and six abnormal areas respectively, but there was no abnormality in TETSP in $\mathrm{K} 12+684-\mathrm{K} 12+661$ section, and TSP303 detection results were more consistent with the actual tunnel excavation results.

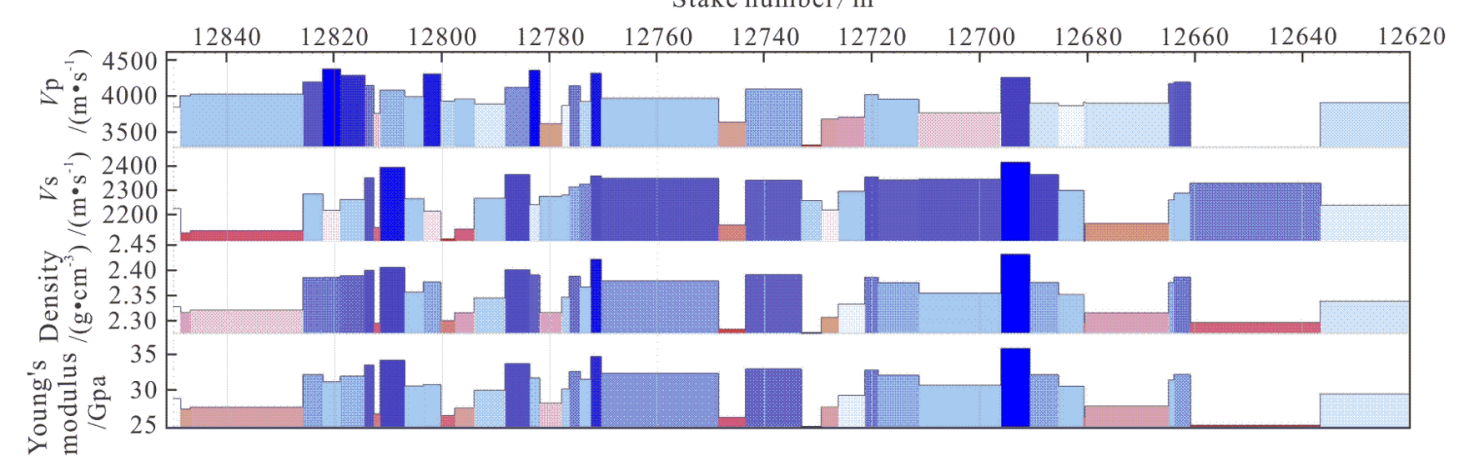

Figure 3. Detection results of TSP303 at stake number K12+850 - K12+620 in ZhangCun tunnel

Table 1. The result analysis of TETSP and TSP303 comparison with tunnel excavation result

\begin{tabular}{|c|c|c|c|c|}
\hline Stake number & $\begin{array}{l}\text { Classifies } \\
\text { quality of } \\
\text { rock } \\
\text { mass }\end{array}$ & Tunnel excavation result & $\begin{array}{l}\text { Prediction results of } \\
\text { TETSP and the } \\
\text { corresponding geological } \\
\text { inferences } \\
\end{array}$ & $\begin{array}{l}\text { Prediction results of } \\
\text { TSP303 and the } \\
\text { corresponding } \\
\text { geological inferences }\end{array}$ \\
\hline $\mathrm{K} 12+850-\mathrm{K} 12+827$ & $\mathrm{III}_{2}$ & $\begin{array}{l}\text { The lithology gradually transits from } \\
\text { sandstone to limestone, with purplish } \\
\text { red argillaceous sandstone locally. The } \\
\text { rock mass is locally soft, and the joints } \\
\text { and fissures with low dip angle are } \\
\text { developed, and some parts are crushed. } \\
\text { The groundwater is mainly seepage } \\
\text { water. }\end{array}$ & \multirow{2}{*}{$\begin{array}{l}\text { The transverse wave and } \\
\text { longitudinal wave } \\
\text { velocity, density and } \\
\text { Young's modulus are } \\
\text { relatively low in section } \\
\mathrm{K} 12+833-\mathrm{K} 12+813 \text {, } \\
\mathrm{K} 12+755-\mathrm{K} 12+738 \text { and } \\
\mathrm{K} 12+655-\mathrm{K} 12+651 \\
\text {, which indicates that the } \\
\text { rock mass is relatively } \\
\text { broken or has strong } \\
\text { dissolution and cave, and }\end{array}$} & \multirow{2}{*}{$\begin{array}{l}\text { The velocity, density } \\
\text { and Young's modulus of } \\
\text { P-wave or S-wave are } \\
\text { relatively low in section } \\
\mathrm{K} 12+848-\mathrm{K} 12+826 \text {, } \\
\mathrm{K} 12+800-\mathrm{K} 12+794 \text {, } \\
\mathrm{K} 12+748-\mathrm{K} 12+744 \text {, } \\
\mathrm{K} 12+733-\mathrm{K} 12+730 \text {, } \\
\mathrm{K} 12+681-\mathrm{K} 12+665 \text {, } \\
\mathrm{K} 12+661-\mathrm{K} 12+637 \text {. It } \\
\text { is speculated that the } \\
\text { rock mass is relatively } \\
\text { broken or developed }\end{array}$} \\
\hline $\mathrm{K} 12+827-\mathrm{K} 12+684$ & $\mathrm{III}_{1}$ & $\begin{array}{l}\text { Greenish gray thick bedded limestone } \\
\text { with good integrity, weak dissolution or } \\
\text { micro joint development, filled with } \\
\text { ferromanganese or rock debris, and a } \\
\text { small amount of water dripping in the } \\
\text { tunnel wall }\end{array}$ & & \\
\hline
\end{tabular}




\begin{tabular}{|l|l|l|l|l|}
$\mathrm{K} 12+684-\mathrm{K} 12+661$ & - & $\begin{array}{l}\text { It is mainly composed of greenish grey } \\
\text { limestone. A large karst cavity is } \\
\text { developed outside the left wall as } \\
\text { shown in Figure 4. The maximum } \\
\text { radius of intersection with the tunnel } \\
\text { face is about } 1 \mathrm{~m} \text {, the cavity is filled } \\
\text { with yellowish brown silty clay } \\
\text { containing fine sand, and some } \\
\text { stalactites are developed on the inner } \\
\text { wall. During the construction process, } \\
\text { there is water seepage on the side of the } \\
\text { left wall near the tunnel face. }\end{array}$ & $\begin{array}{l}\text { with karst caves and } \\
\text { strong dissolution, and } \\
\text { ane rock mass contains } \\
\text { water locally. }\end{array}$ \\
\hline $\mathrm{K} 12+661-\mathrm{K} 12+620$ & $\mathrm{~V}$ & $\begin{array}{l}\text { It is greenish grey limestone. The } \\
\text { filling type karst cave is developed near } \\
\text { the top of the left side of the face as } \\
\text { shown in figure 4. The filling material } \\
\text { is mainly silty clay containing fine sand } \\
\text { and gravel, and the rock mass is poor in } \\
\text { stability }\end{array}$ & \\
\hline
\end{tabular}

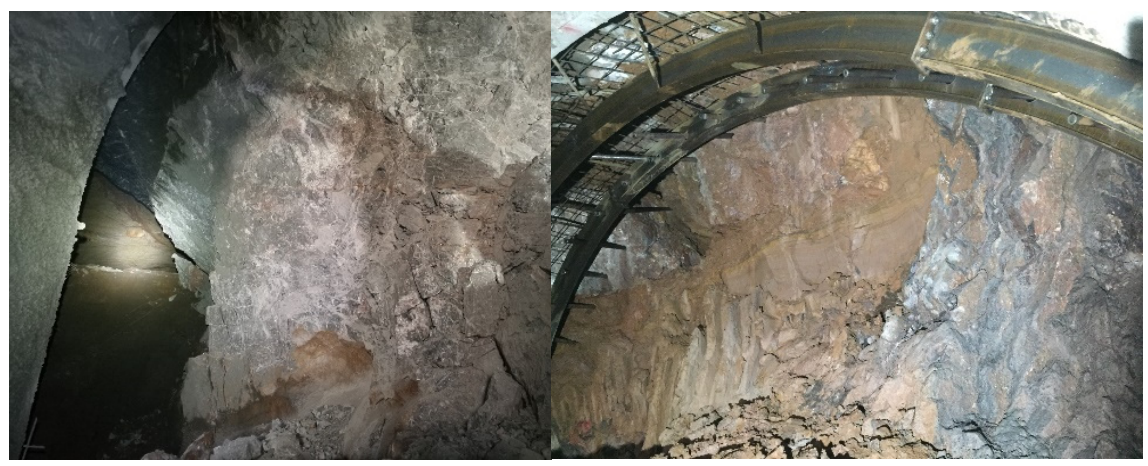

(a) The exposed karst cave in the left side of tunnel wall near stake number K12+664

(b) The exposed mud filled karst cave in the left side of tunnel face near stake number K12+641

Figure 4. Karst cave exposed by tunnel excavation

\section{Conclusion}

Firstly, TETSP geophone is more sensitive than conventional tunnel geological prediction method. In the hard rock prediction process, the explosive amount can be appropriately reduced to prevent energy overflow. The installation efficiency of TETSP clay coupling geophone is higher than that of TSP303.

Secondly, TETSP uses zero filling method to remove acoustic interference from the reflected signal after the first arrival time of sound wave, which can significantly improve the signal-to-noise ratio of the data for the signal with poor quality, TSP303 is suitable for seismic reflection data processing under strong acoustic interference conditions. TSP303 uses two dimensional filtering method to suppress interference signals. If the quality of data acquisition is good, TSP303 can meet both detection accuracy and prediction distance.

Thirdly, TETSP and TSP303 are suitable for geological prediction with developed dissolution tunnel. The case in this paper shows that TSP303 has better prediction effect, the areas with low velocity, density and Young's modulus of seismic reflection method correspond to strong corrosion or karst cave.

\section{Acknowledgments}

This work was supported by the Science and Technology Project of Zhejiang Provincial Water Resources Department (RC1951)

\section{References}

1. Li, S. C, Zhou, Z. Q Li, L. P (2015) Comprehensive geophysical prediction and treatment measures of karst caves in deep buried tunnel[J]. Journal of applied geophysics, 116(5): 247 - 257.

2. Tian, G Bai, M. Z, Wang, C. L (2016) The threedimensional imaging technology and its improvement for geological structure based on the TRT system[J]. Chinese Journal of geophysics, 59(7): 2684 - 2693.

3. Liu, Y. Z Mei, R. W (2011) Advantages of TGP advance geology prediction technology in tunnels[J]. Tunnel Construction, 31(01):21 - 32 .

4. Zhao, Y. G Jiang, H Zhao, X. P (2006) Tunnel seismic tomography method for geological prediction and its application[J]. Applied Geophysics, 3(2): $69-74$.

5. Cao, G. H Wang, Y. S Li, Y. H (2014) Application of three - dimensional imaging system for forecasting 
geological disasters in underground engineering[J]. Chinese Journal of Underground Space and Engineering, 10(s1):1735 - 1739.

6. Zhao, G. J Li, J. J Jiang, Z. G (2018) Application of AGI - T3 to advance geological prediction for construction of water conveyance tunnel[J]. Water Resources and Hydropower Engineering, 49(6): 164 $-170$.

7. Wang, Y Fu, N. Y and Lu, X. L (2019) Application of a new geophone and geometry in tunnel seismic detection[J]. Sensors, 19(5): $1246-1260$. 